5 Barksdale, A. W., Am. J. Bot., 47, 14 (1960).

${ }^{6}$ Barksdale, A. W., Mycologia, 55, 627 (1963).

7 Barksdale, A. W., Ann. N.Y. Acad. Sci., 144, 313 (1967).

${ }^{8}$ Barksdale, A. W., Science, 166, 831 (1969).

${ }^{9}$ Machlis, L., Physiol. Pl., 11, 181 (1958).

10 Machlis, L., Physiol. Pl., 11, 845 (1958).

11 Bistis, G., Am. J. Bot., 43, 389 (1956).

12 Bistis, G., Am. J. Bot., 44, 436 (1957).

${ }^{13}$ Bistis, G., and Raper, J. R., Am. J. Bot., 50, 880 (1963).

14 Banbury, G. H., Nature, 173, 499 (1954).

15 Banbury, G. H., Expl Bot., 6, 235 (1955).

16 Plempel, M., Arch. Microbiol., 25, 154 (1957).

17 Plempel, M., Naturwissenchaften, 47, 472 (1960).

18 Plempel, M., and Braunitzer, G., Z. Naturb., 13b, 302 (1958).

19 Gooday, G. W., Phytochemistry, 7, 2103, (1968).

${ }^{20}$ Gooday, G. W., New Phytol. 67, 815, (1968).

${ }^{21}$ Levi, J. D., Nature, 177, 753 (1956).

${ }^{22}$ Yanagashima, N., Planta, 87, 110 (1969).

${ }^{23}$ Yanagashima, N., Physiol. Pl., 24, 260 (1971).

24 Ito, T., Bot. Mag. Tokyo, 69, 369 (1956).

25 Howe, jr., H. B., and Prakash, V., Can. J. genet. Cytol., 11, 689 (1969).

${ }^{26}$ Vigfusson, N. V., Walker, D. G., Islam, M. S., and Weijer, J., Folia Microbiol. 16, 166 (1971).

27 Islam, M. S., and Weijer, J., Folia Microbiol. 17, 316 (1972).

${ }^{28}$ Ende, H. van den, J. Bact., 96, 1298 (1968).

${ }^{29}$ Plempel, M., Planta, 59, 492 (1963).

30 Duntze, $\$$. ., Mackay, V., and Manney, T. R., Science, 168, 1472 (1970).

${ }^{31}$ Ende, H. van den, and Stegwee, D., Bot. Revs., 37, 22 (1971).

32 Westergard, M., and Mitchell, H. K., Am. J. Bot., 34, 573 (1947).

${ }^{33}$ Machlis, L., Mycologia, 64, 235 (1972).

${ }^{34}$ Ende, H. van den, Weichmann, A. H. C. A., Reyngoud, D. J., and Hendricks, T., J. Bact., 101, 423 (1970).

\section{Bacteria can swim without rotating flagellar filaments}

THERE are two simple ways in which the observed screw-like propulsive motion of bacterial flagella can be understood. Either, first, the flagellum is like a rigid corkscrew rotating in a sort of journal bearing in the cell wall (hypothesis $A$ ) or, second, the flagellum is firmly attached to the cell wall and moves by the propagation of helical waves (hypothesis B).

Berg and Anderson ${ }^{1}$ argue in favour of hypothesis $A$. Their most positive argument involves the idea that in multiflagellated bacteria a bivalent antibody firmly attaching itself to two neighbouring flagella would prevent motion according to hypothesis $A$ but not on hypothesis $B$. Thus, they interpret the observations of Di Pierro and Doetsch ${ }^{2}$ on the effect of univalent and bivalent flagellar antibodies on both peritrichous and uniflagellar bacteria as support for the 'rotating corkscrew' picture of flagellar motion.

Unfortunately, they have left out of their analysis a simple geometrical factor, which altogether removes from their argument the power to discriminate between the two hypotheses.

Figure 1 (based on Fig. 1 Berg and Anderson ${ }^{1}$ ) shows two cross-sectional views (Fig. $1 a$ and $b$ ) along the helical axes of two neighbouring filaments at two successive instants of time according to hypotheses $A$ and $B$ respectively. In Fig. $1 a$ the cross sections rotate, whereas in Fig. $1 b$ they do not. The difference in pattern of relative motion of the spots marked on the surfaces of adjacent filaments is plain.

But now consider Fig. $1 a^{\prime}$ and $b^{\prime}$, which show projected 'elevations' of the situations depicted in Fig. $1 a$ and $b$. Again the spots are shown but on short segments of the neighbouring filaments in this view. Notice the relative motion of the spots in Fig. $1 b^{\prime}$ along the local filament axis, which is not apparent in the view in Fig. $1 b$ alone. A bivalent antibody attached to the two spots in Fig. $1 b$ and $b^{\prime}$ could therefore inhibit motion just as strongly as it could in Fig.

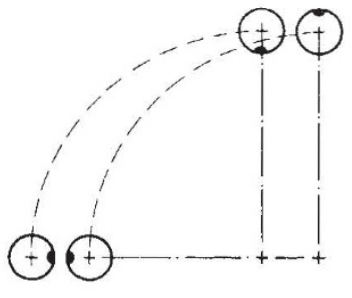

$a$
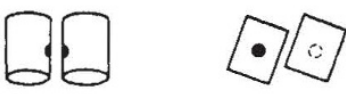

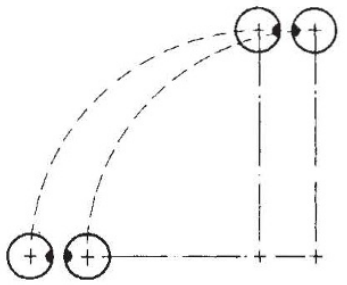

$b$
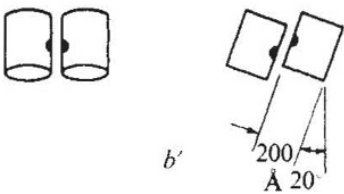

Fig. 1 A schematic view of two adjacent filaments rotating individually ( $a$ and $a^{\prime}$ ) or propagating helical waves ( $b$ and $b^{\prime}$ ) at two successive intervals of time, $a$ and $b$ Are sectional vews in a plane normal to the helical axes $(+)$. $a^{\prime}$ and $b^{\prime}$ Are elevations of segments of the filaments, projected from $a$ and $b$ in the plane of the helical axes.

$1 a$ and $a^{\prime}$. The relative motion of the spots on hypothesis $B$ is an oscillatory lengthwise rubbing, and we can estimate its amplitude easily by taking the helix angle in Fig. $1 b^{\prime}$ as about $20^{\circ}$ and the diameter of the filaments as about $200 \AA$, after Asakura ${ }^{3}$. Then the extreme displacement of one spot to another is $\pm 70 \AA$, that is a total throw of $140 \AA$ or about three times the diameter of a flagellin subunit.

Hence, the fact that bivalent flagellar antibodies 'lock' adjacent filaments can only be taken to rule out hypothesis $B$ if the antibodies are flexible, and indeed much more flexible than seems likely from what is known about their size and construction.

Now antibodies have a Y-shaped form, with two arms which attach to the host at the tips ${ }^{4}$. From an X-ray crystallographic investigation of the $\mathrm{Fab}^{\prime}$ fragment of an antibody Padlan et $a l^{5}$ have determined its overall length to be $80 \AA$. Thus the length of an arm can be assumed to be about $70 \AA$. It seems likely that the tips are attached to the host with strong restrictions on the angle of attachment, and so it is difficult to see how such a molecule could stay attached to two points on adjacent flagella executing the large relative motion I have described without having extremely flexible arms.

The arguments of Berg and Anderson therefore do not prove that hypothesis $B$ is wrong. Indeed, I believe hypothesis $B$ to be correct because the propagation of helical waves in a filament requires only small relative movements between adjacent flagellin subunits, whereas a rigid-body motion of the entire filament would require a very specially constructed bearing. Moreover, as $\mathrm{Klug}^{6}$ has pointed out, the problem of propagating a helical wave in a filament is largely subsumed in the problem of assembling a helical filament from identical flagellin subunits, which would still be an outstanding problem on hypothesis $A$.

I thank Dr A. Klug for help.

Department of Engineering,

C. R. Calladine

University of Cambridge,

Trumpington Street,

Cambridge CB2 $1 P Z, U K$

Received January 30, 1974.

1 Berg, H. C., and Anderson, R. A., Nature, 245, 380-382 (1973).

2 Di Pierro, J. M., and Doetsch, R. N., Can. J. Microbiol., 14, 487-489 (1968).

3 Asakura, S., Adv. Biophys., 1, 99-155 (1970).

4 Green, N. M., Adv. Immun., 11, 1-30 (1969).

${ }^{5}$ Padlan, E. A., Segal, D. M., Spande, T. F., Davies, D. R. Rudikoff, S., and Potter, M., Nature new Biol., 245, 165-167 (1973).

6 Klug, A., Symp. int. Soc. Cell Biol., 6, 1-18 (1967). 